\title{
Contraceptive use and method preference among HIV-positive women in Amhara region, Ethiopia
}

\author{
Kefyalew Addis Alene ${ }^{1 *}$ and Kendalem Asmare Atalell ${ }^{2}$
}

\begin{abstract}
Background: Providing preferred methods of contraceptive for HIV-positive women and avoiding unintended pregnancy is one of the primary means of preventing mother to child transmission of HIV. This study assessed the prevalence of contraceptive use and method preference among HIV-positive women in Amhara region, Ethiopia.

Methods: A cross-sectional survey was conducted among HIV-positive women in three referral hospitals of Amhara region. Data were collected by interviewing HIV-positive women using a pre-tested and structured questionnaire. A binary logistic regression model was used to identify factors associated with contraceptive use, and odd ratio with 95\% confidence interval (Cl) was calculated to measure the strength of association.

Results: A total of 803 women living with HIV (with a response rate of 95.4\%) were interviewed. The mean age of the study participants was 32.2 years (SD \pm 6.2 years). The prevalence of current contraceptive use was 30.3\% (95\% $\mathrm{Cl}$ : 27.0-33.7\%). The preferred and most commonly used contraceptive methods were injectable (42.8\%) and male condom (32.9\%). Younger age group (15-24 years) ( $A O R=9.67 ; 95 \% \mathrm{Cl}: 3.45,27.10)$, one or more number of living children ( $\mathrm{AOR}=4.01 ; 95 \% \mathrm{Cl}: 2.07,7.79)$, $\mathrm{HIV}$ diagnosis $>2-4$ years $(\mathrm{AOR}=2.37 ; 95 \% \mathrm{Cl}: 1.10,5.08)$, and having high CD4 count $>500$ cell/ul $(A O R=3.25 ; 95 \% \mathrm{Cl}: 1.42,7.44)$ were significantly associated with contraceptive use.

Conclusion: The prevalence of contraceptive use among HIV-positive women in Amhara region referral hospitals is low, which suggests a high risk of unintended pregnancy. Injectable and male condoms are the most preferred type of contraceptive methods. Thus, it is better to integrate these contraceptive methods with ART clinic.
\end{abstract}

Keywords: Contraceptive, Family planning, HIV/AIDS, Women, Ethiopia

\section{Background}

Among HIV infected pregnant women, living in subSaharan Africa, around $50-80 \%$ of pregnancy is unintended $[1,2]$. A study has shown that without any intervention, between 25 and $45 \%$ of HIV-positive women living in resource constraint settings transmit HIV to their babies during pregnancy $(5-10 \%)$, delivery $(10-20 \%)$, or through breastfeeding (10-20\%) [3]. Almost half of the children who acquired HIV infection from their mothers die before their second birthday [3].

Preventing unintended pregnancy among HIV-positive women by providing suitable family planning methods is a

\footnotetext{
*Correspondence: kefadis@gmail.com

'Institute of Public Health, College of Medicine and Health Sciences,

University of Gondar, Gondar, Ethiopia

Full list of author information is available at the end of the article
}

critical and cost-effective approach for primary prevention of mother-to-child transmission (PMTCT) of HIV [4]. A cost-effectiveness study has reported that a PMTCT strategy focused on increasing contraception among HIV-positive women could avert 29\% more HIV-positive births than prophylactic nevirapine alone, at the same level of expenditure [5]. Preventing unintended pregnancy is a global public health priority for addressing maternal and child health problem in HIV hyper-endemic settings. Addressing the current desperate state of maternal and child health in sub-Saharan Africa is a global public health priority [6]. Central to this agenda is the prevention of unintended pregnancy through increasing access to and use of effective contraception [4]. Although the provision of contraceptive services to HIV-positive women is a critical

(c) The Author(s). 2018 Open Access This article is distributed under the terms of the Creative Commons Attribution 4.0 International License (http://creativecommons.org/licenses/by/4.0/), which permits unrestricted use, distribution, and 
strategy to prevent unintended pregnancy [7], it is mostly neglected in several settings [8].

The emerging reality of HIV as a manageable chronic disease, with HIV-infected individuals anticipated to live longer and reach their reproductive years, has highlighted the importance of assessing the potential behavioural and biological impacts of ART on contraceptive use and safety $[9,10]$.

Ethiopia has developed a national guideline on PMTCT of HIV infection. The guideline emphasizes primary prevention of HIV infection and prevention of unintended pregnancies among HIV -infected women [11]. Following the development of this guideline, progress has been observed in the implementation of PMTCT services, and the number of pregnant mothers who receive PMTCT services has increased [12]. However, the overall coverage of PMTCT remains as low as $24 \%$ of the expected eligible population [13]. According to the United Nations report, Ethiopia is stated as one of 22 priority countries for eliminating mother-to-child transmission of HIV [14]. The number of pregnant women tested and found to be HIV-positive was 20,755 in 2010-2011; however, only 8365 received antiretroviral drugs (ARVs) [15]. Similarly, only 4945 children born to HIV-infected mothers have received ARV prophylaxis [15]. The reasons for low coverage need to be addressed, and PMTCT uptake needs to be closely linked with efforts to expand coverage of maternal and child health services through the provision of contraceptive [16]. Women with HIV infection, like other women, may wish to plan a pregnancy, limit their family, or avoid unintended pregnancy. However, contraceptive use and method of preference have not been well studied, especially in Amhara region, Ethiopia. Therefore, this study aimed to assess contraceptive use and methods of preference among HIV-positive women.

\section{Methods}

\section{Study design and setting}

A cross-sectional survey was conducted among HIV-positive women in Amhara region, Ethiopia in May 2013. Amhara region is the second largest region in Ethiopia and comprises $23.4 \%$ of the total population of the country [17]. The region has five referral hospitals, and the study was conducted in three of these five referral hospitals: Gondar University Referral Hospital, Dessie Referral Hospital, and Debremarkos Referral Hospitals. Two of the hospitals are under the administration of Amhara Regional State Health Bureau, and the other, Gondar University Referral Hospital is a university hospital under the administration of the Federal Ministry of Health.

Debremarkos Referral Hospital is located in East Gojam, $305 \mathrm{~km}$ Northwest of Addis Ababa (the capital city of Ethiopia). In the hospital, a total of 8478 people living with HIV (PLHIV) were ever enrolled in the ART clinic, and a total of 1421 women were on ART during the data collection period.

Gondar University Hospital is the oldest hospital in the country and is located in Northwest Ethiopia. It provides health care services for a catchment population of approximately five million people in North Gondar and the adjacent zones. The hospital established HIV care service in 2005 that contains three clinics (i.e. Adult ART clinic, Pediatric ART clinic, and Voluntary Counseling and Testing (VCT) clinic). A total of 10,600 PLHIV were ever enrolled in the ART clinic, and a total of 2562 women were on ART during the data collection period.

Dessie Referral Hospital is located in North Wollo, $400 \mathrm{~km}$ Northeast of Addis Ababa. The hospital serves as a referral centre for more than five million people in its catchment area. In the hospital, during the data collection period, a total of 15,985 PLHIV were ever enrolled in ART clinic, and 3015 women were on ART.

\section{Inclusion and exclusion criteria}

Participants were eligible if they were HIV-positive women, aged 15 to 49 years, enrolled in chronic HIV care in the three hospitals (i.e. Gondar, Dessie and Debremarkos referral hospitals), and had at least one visit to the ART unit. HIV-positive women who were pregnant during the data collection period were excluded from the study.

\section{Sample size and sampling procedures}

The sample size for this study was determined using single population proportion formula, by taking the following assumptions: $53.5 \%$ contraceptive use among HIV-positive women (from a study conducted at six public hospitals in Addis Ababa, Ethiopia [18]), 5\% margin of error, 2 design effect, 10\% contingency, and 95\% confidence interval. Based on these assumptions, the final sample size was 842. Multistage sampling technique was used to select the study participants. First, three among the five hospitals in Amhara region were selected randomly (i.e. Gondar University Referral Hospital, Debremarkos Referral Hospital and Dessie Referral Hospital). The samples were then proportionally allocated to each hospital. Finally, respondents were selected using systematic random sampling technique.

\section{Data collection tools and procedures}

Data were collected by interviewing HIV-positive women using structured and pre-tested questionnaire. The questioner used in our study was developed for the purpose of this study. It was first prepared in English and then translated into local language (Amharic). The English version of the questionnaire is available as an Additional file 1. Women were interviewed, at the hospitals during their follow up visit, regarding demographics, contraceptive use, HIV and medical history. One supervisor and two data collectors at each hospital, with a total of nine 
Table 1 Socio-demographic characteristics of study participants, in Amhara region referral hospitals, Ethiopia, May $2013(n=803)$

\begin{tabular}{lll}
\hline Variables & Frequency & Percent \\
\hline Hospital & & \\
Gondar & 298 & 37.1 \\
Dessie & 344 & 42.8 \\
Debre Markos & 161 & 20.0 \\
Age group (years) & & \\
15-24 & 67 & 8.3 \\
25-29 & 197 & 24.5 \\
30-34 & 212 & 26.4 \\
35-39 & 202 & 25.5 \\
40-49 & 125 & 15.6 \\
Residence & & \\
Urban & 729 & 90.8 \\
Rural & 74 & 9.2
\end{tabular}

Marital status

Single

Married

Divorced

Widowed

Separated

Religion

Orthodox Christian 539

Muslim

Protestant

Others

Ethnicity

Amhara

Tigray

Others

Educational level

Not able to read and write

Able to read and write

Primary school (1-8)

Secondary School (9-12)

College or University level

Occupation

Daily labourer

Farmer

Government employee

Housewife

Merchant

Others

Monthly household income (EBR) ${ }^{a}$

$$
<300.00
$$

6.8

43.5

24.0

22.9

2.7

67.1

30.8

2.0

0.1

96.8

2.6

0.6

27.1

19.6

20.2

27.3

5.9

24.4

7.3

8.8

35.1

15.7

8.6
Table 1 Socio-demographic characteristics of study participants, in Amhara region referral hospitals, Ethiopia, May $2013(n=803)$ (Continued)

\begin{tabular}{lll}
\hline Variables & Frequency & Percent \\
\hline 300.00-600.00 & 191 & 23.8 \\
$601.00-1000.00$ & 232 & 28.9 \\
$>1000.00$ & 161 & 20.0 \\
\hline${ }^{\mathrm{a} E B R}$, Ethiopian Birr; Exchanger rate, \$ 1 = 18.07 EBR &
\end{tabular}

personnel, were participated in the data collection process. To maintain the quality of the data, intensive training was given to the data collectors and supervisors. The data collection process was monitored by the principal investigator. Prior to the main survey, the questioner was pre-tested to assess its clarity and suitability to the study participants. The pre-test was undertaken outside the study sites among $40 \mathrm{HIV}$-positive women (i.e. 5\% of the sample). Participants interviewed in the pre-test were not included in the main study.

\section{Data processing and analysis}

The data were checked for its completeness, entered into Epi Info version 3.5.3, and exported to SPSS version 20.0 software for analysis. Descriptive and summary statistics were calculated. Categorical variables were presented as numbers and percentages, normally distributed continuous variables were presented as mean and standard deviation (SD), and non-normally distributed continuous variables were presented as median and interquartile range (IQR). Bivariate logistic regression models were first performed using demographic and clinical variables. Variables which had a $p$ value $<0.2$ in the bivariate analysis were then fitted in the final multivariate logistic regression model. Crude and adjusted odds ratios with $95 \% \mathrm{CI}$ were calculated to measure the strength of association between the dependent and independent variables.

\section{Results}

Socio-demographic characteristics

A total of 803 HIV-positive women were participated in the interview, with a response rate of $95.4 \%$. The mean age of the women was 32.2 years $(\mathrm{SD}=6.2)$, and the majority of the women $(729 ; 90.8 \%)$ were an urban dweller. More than one third $(298 ; 37.1 \%)$ were from Gondar University Referral Hospital, 344 (42.8\%) were from Dessie Referral Hospital, and 161 (20.0\%) were from Debremarkos Referral Hospital. Almost half of the study participants (349; 43.5\%) were married. Two-thirds of the women had less than primary education, $282(35.1 \%)$ were housewives, and 219 (27.3\%) had a monthly household income less than 300 Ethiopian birr (EBR) (i.e. $<\$ 16.6$ ). Amhara (96.8\%) and Orthodox Christianity (67.1\%) were the dominant ethnicity and religion respectively (Table 1 ). 


\section{HIV infection and reproductive history of women}

Half of the study participants $(395 ; 49.2 \%)$ had less than three family sizes, one or two previous life birth (405; $50.4 \%$ ), and one or two surviving children (410; 50.1\%). Majority of the women $(571 ; 71.1 \%)$ did not give birth after HIV infection, 66 (8.2\%) had an HIV-positive child, and two-thirds $(549 ; 68.4 \%)$ did not desire future pregnancy. The median CD4 count was 420 cell/ul (IQR $=300-570$ ), and the median time since HIV diagnosis was five years $(\mathrm{IQR}=3-6)$. Almost all of the married women (349; 97.9\%) disclosed their HIV status to their husband, and most of their husbands were HIV-positive (73.6\%) (Table 2).

\section{Prevalence of contraceptive use}

The overall prevalence of current contraceptive use was $30.3 \%$ (95\% CI: $27.0-33.7 \%$ ). The prevalence of contraceptive use among 560 women who do not want to get pregnancy was $31.1 \%(n=171)$. Of the 243 women reporting contraceptive use, $36 \%$ used contraceptive for 3-5 years. The most commonly used and preferred methods of contraceptive were injectable (42.8\%) and male condom (32.9\%), followed by the implant (11.1\%). Contraceptive use among women before HIV infection was $66.3 \%$ and the most commonly used methods were injectable and oral contraceptive (pills). Three hundred and twenty-five women have future need to use a contraceptive. The commonest places where HIV-positive women get contraceptive were at family planning (42.2\%), and ART (41.2\%) clinic; however, two-thirds of the study participates preferred to get contraceptive at the ART clinic of the hospital. The women were the main decision maker to use contraceptive (Table 3).

\section{Factors associated with contraceptive use}

In the bivariate analysis, study settings (i.e. hospitals), age of women, marital status, educational level, monthly household income, family size, number of surviving children, giving birth after HIV infection, has or had an HIV-positive child, time since HIV diagnosis and current CD4 count were significantly associated with contraceptive use. However, in the multivariate analysis, the age of women, study settings, marital status, monthly household income, number of surviving children and current CD4 count were remained significantly and independently associated with contraceptive use.

Accordingly, those HIV-positive women who enrolled at Dessie Referral Hospital were less likely to use contraceptive than women who enrolled at Gondar Referral Hospital (AOR $=0.34 ; 95 \%$ CI: 0.19, 0.51). Those women in the age group of $15-24$ years $(\mathrm{AOR}=9.67$; $95 \% \mathrm{CI}$ : $3.45-27.10), 25-29$ years $(\mathrm{AOR}=5.86$; $95 \% \mathrm{CI}: 2.71,12.66$ ), 30-34 (AOR $=3.42$; 95\% CI: $1.64,7.11)$ were more likely to use contraceptive as compared to those women with the age group of 40-49 years.
Table 2 HIV infection and reproductive history of women, in Amhara region referral hospitals, may 2013

\begin{tabular}{|c|c|c|}
\hline Variables & Number & Percent \\
\hline \multicolumn{3}{|l|}{ Family Size } \\
\hline$<3$ & 395 & 49.2 \\
\hline $3-5$ & 326 & 40.6 \\
\hline$>5$ & 82 & 10.2 \\
\hline \multicolumn{3}{|c|}{ Previous life birth } \\
\hline 0 & 127 & 15.8 \\
\hline $1-2$ & 405 & 50.4 \\
\hline $3-4$ & 215 & 26.8 \\
\hline $5+$ & 56 & 7.0 \\
\hline \multicolumn{3}{|c|}{ Number of living children } \\
\hline 0 & 158 & 19.7 \\
\hline $1-2$ & 410 & 50.1 \\
\hline $3-4$ & 199 & 24.8 \\
\hline $5+$ & 36 & 4.5 \\
\hline \multicolumn{3}{|c|}{ Desires of future pregnancy } \\
\hline Yes & 254 & 31.6 \\
\hline No & 549 & 68.4 \\
\hline \multicolumn{3}{|c|}{ Give birth after HIV infection } \\
\hline Yes & 232 & 28.9 \\
\hline No & 571 & 71.1 \\
\hline \multicolumn{3}{|c|}{ Has or had an HIV-positive child } \\
\hline Yes & 66 & 8.2 \\
\hline No & 677 & 84.3 \\
\hline I don't know & 60 & 7.5 \\
\hline \multicolumn{3}{|c|}{ Time since HIV diagnosis (years) } \\
\hline$\leq 1$ year & 86 & 10.7 \\
\hline $2-3$ years & 301 & 37.5 \\
\hline$\geq 4$ years & 416 & 51.8 \\
\hline \multicolumn{3}{|c|}{ Current CD4 count } \\
\hline$<200$ & 78 & 9.7 \\
\hline $200-350$ & 215 & 26.8 \\
\hline $351-500$ & 251 & 31.3 \\
\hline$>500$ & 259 & 32.3 \\
\hline \multicolumn{3}{|c|}{ HIV status of a husband $(n=349)$} \\
\hline Positive & 257 & 73.6 \\
\hline Negative & 76 & 21.8 \\
\hline Unknown & 16 & 4.6 \\
\hline \multicolumn{3}{|c|}{ Disclosed HIV status to partner(349) } \\
\hline Yes & 342 & 97.9 \\
\hline No & 7 & 2.1 \\
\hline
\end{tabular}

Monthly family income is the other variable which has an association with contraceptive use. Those women whose family monthly incomes 300.00-600.00 EBR were less 
Table 3 Contraceptive use among HIV-positive women, in Amhara region referral hospitals, May 2013

\begin{tabular}{lll}
\hline & Number & Percent \\
\hline Current use of contraceptive & & \\
Yes & 242 & 30.1 \\
No & 561 & 69.9
\end{tabular}

Type of currently used contraceptive $(n=243)$

$\begin{array}{lll}\text { Injectable } & 104 & 42.8 \\ \text { Male condom } & 80 & 32.9 \\ \text { Implants } & 27 & 11.1 \\ \text { IUD } & 15 & 6.2 \\ \text { Oral contraceptives } & 12 & 4.9 \\ \text { Calendar } & 2 & 0.8 \\ \text { Lactational Amenorrhea } & 1 & 0.4 \\ \text { Others } & 2 & 0.8\end{array}$

Time since current contraceptive started $(n=242)$

$\begin{array}{lcc}<6 \text { month } & 12 & 4.9 \\ 6-12 \text { months } & 56 & 23.0 \\ 1-2 \text { years } & 57 & 23.4 \\ 3-5 \text { years } & 87 & 35.8 \\ \geq 6 \text { years } & 31 & 12.8 \\ \text { Preference method of contraceptive }(n=243) & \\ \text { Yes } & 237 & 97.5 \\ \text { No } & 6 & 2.5\end{array}$

Place of getting contraceptive in the hospital $(n=243)$

$\begin{array}{lll}\text { FP clinic } & 103 & 42.2 \\ \text { ART clinic } & 100 & 41.2 \\ \text { Not available in the hospital } & 36 & 14.8 \\ \text { Others } & 4 & 1.6\end{array}$

Preferred place of getting contraceptive in the hospital $(n=243)$

$\begin{array}{lll}\text { FP clinic } & 47 & 19.3 \\ \text { ART clinic } & 183 & 75.3 \\ \text { TB clinic } & 1 & 0.4 \\ \text { Others } & 14 & 5.7\end{array}$

Decision maker to use contraceptive $(n=243)$

Women 191

Partner

Health professional

Others

Contraceptive use prior to HIV infection

$$
\text { Yes }
$$

$$
532
$$

No

271

Type of contraceptive used prior to HIV infection

IUD

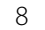

Injectable

8

Norplant
Table 3 Contraceptive use among HIV-positive women, in Amhara region referral hospitals, May 2013 (Continued)

\begin{tabular}{lll}
\hline & Number & Percent \\
\hline Oral contraceptive/pills & 140 & 26.3 \\
Male condom & 11 & 2.0 \\
Calendar & 1 & 0.2 \\
Future needs for contraceptive & & \\
Yes & 325 & 40.5 \\
No & 370 & 46.1 \\
Not sure & 108 & 13.4 \\
\hline
\end{tabular}

likely to use contraceptive than women whose monthly income < 300.00EBR (AOR $=0.47 ; 95 \% \mathrm{CI}$ : 0.45, 0.87).

The number of living children is also another determinant factor which has an association with contraceptive use. Women who had 1-2 and 3-4 living children were more likely to use contraceptive as compared to women who had no surviving children $(\mathrm{AOR}=4.0 ; 95 \% \mathrm{CI}$ : $2.07,7.79$ ) and (AOR $=3.11 ; 95 \% \mathrm{CI}: 1.38,7.00$ ), respectively.

Duration of HIV diagnosis is also significantly associated with contraceptive use. Those women who have been diagnosed for HIV for a long period (4 years and above) were more likely to use contraceptive as compared to those with infection less than one years (AOR $=2.63 ; 95 \% \mathrm{CI}: 1.23,5.61)$.

Women with a relatively high CD4 count (>500 cell/ul) were more likely to use contraceptive as compared to low CD4 count $(<200 \mathrm{cell} / \mathrm{ul})(\mathrm{AOR}=3.25 ; 95 \% \mathrm{CI}: 1.42,7.44)$ (Table 4).

\section{Discussion}

The prevention of unintended pregnancies among HIV infected women is highly dependent on the use of contraceptive. In our study, the overall prevalence of contraceptive use among HIV infected women was $30.3 \%$. This finding is lower than reported prevalence of contraceptive use among reproductive age group women in Ethiopia (36\%), and Amhara region (47\%) [19]. It is also lower than studies conducted in Brazil (49\%), South Africa (53.5\%) and Addis Ababa (78\%) [20-22]. The lower prevalence of contraceptive use in our study might be explained by the high level of desire for children among the married women, and low levels of sexual desire among the separated, divorced and widowed women. The other reason for the low prevalence of contraceptive use among HIV-positive women could be due to unavailability of the preferred types of contraceptive methods at ART clinics.

Contraceptive methods preferred by women may have implications for both HIV transmission and risks of unintended pregnancy [23, 24]. Although a condom is recommended to prevent HIV transmission to uninfected sexual partners, it is less effective than hormonal contraception and sterilisation at avoiding pregnancy [25]. In 
Table 4 Factors associated with contraceptive use among HIV-positive women in Amhara region referral hospitals, May 2013

\begin{tabular}{|c|c|c|c|c|}
\hline \multirow[t]{2}{*}{ Variables } & \multicolumn{2}{|c|}{ Contraceptive use } & \multirow[t]{2}{*}{ COR $(95 \% \mathrm{Cl})$} & \multirow[t]{2}{*}{$\mathrm{AOR}(95 \% \mathrm{Cl})$} \\
\hline & Yes & No & & \\
\hline \multicolumn{5}{|l|}{ Hospital } \\
\hline Gondar & 90 & 208 & $1: 00$ & $1: 00$ \\
\hline Dessie & 92 & 252 & $0.84(0.59,1.19)$ & $0.34(0.19,0.51)$ \\
\hline Debre markos & 61 & 100 & $1.41(0.94,2.11)$ & $1.24(0.70,2.20)$ \\
\hline \multicolumn{5}{|l|}{ Age group (years) } \\
\hline $15-24$ & 22 & 45 & $2.90(1.42,5.93)$ & $9.67(3.45,27.10)$ \\
\hline $25-29$ & 84 & 113 & $4.41(2.49,7.84)$ & $5.86(2.71,12.66)$ \\
\hline $30-34$ & 77 & 135 & $3.39(1.91,6.01)$ & $3.42(1.64,7.11)$ \\
\hline $35-39$ & 42 & 160 & $1.56(0.85,2.85)$ & $1.99(0.93,4.26)$ \\
\hline $40-49$ & 18 & 107 & $1: 00$ & $1: 00$ \\
\hline \multicolumn{5}{|l|}{ Marital status } \\
\hline Married & 147 & 202 & $1: 00$ & $1: 00$ \\
\hline Single & 47 & 8 & $8.07(3.70,17.59)$ & $0.98(0.03,0.26)$ \\
\hline Divorced & 172 & 21 & $0.17(0.29,1.72)$ & $0.05(0.03,0.10)$ \\
\hline Widowed & 178 & 6 & $0.19(0.06,0.59)$ & $0.01(0.01,0.04)$ \\
\hline Separated & 16 & 6 & $2.20(0.66,7.32)$ & $0.12(0.04,0.37)$ \\
\hline \multicolumn{5}{|l|}{ Religion } \\
\hline Orthodox Christian & 177 & 362 & $1: 00$ & \\
\hline Muslim & 62 & 185 & $0.68(0.48,0.96)$ & \\
\hline Protestant & 4 & 13 & $0.62(0.20,1.95)$ & \\
\hline \multicolumn{5}{|l|}{ Educational level } \\
\hline Not able to read and write & 64 & 154 & $0.61(0.31,1.17)$ & \\
\hline Able to read and write only & 39 & 118 & $0.48(0.24,0.96)$ & \\
\hline Primary school (1-8) & 46 & 116 & $0.58(0.29,1.14)$ & \\
\hline Secondary School (9-12) & 75 & 144 & $0.76(0.40,1.46)$ & \\
\hline College or University level & 19 & 28 & $1: 00$ & \\
\hline \multicolumn{5}{|l|}{ Monthly household income (EBR) ${ }^{a}$} \\
\hline$<300.00$ & 53 & 166 & $1: 00$ & $1: 00$ \\
\hline $300.00-600.00$ & 47 & 144 & $1.02(0.65,1.60)$ & $0.47(0.45,0.87)$ \\
\hline $601.00-1000.00$ & 64 & 168 & $1.19(0.78,1.82)$ & $0.55(0.30,1.00)$ \\
\hline$>1000.00$ & 79 & 82 & $3.01(1.94,4.67)$ & $0.57(0.30,1.07)$ \\
\hline \multicolumn{5}{|l|}{ Number of living children } \\
\hline 0 & 22 & 136 & $1: 00$ & $1: 00$ \\
\hline $1-2$ & 148 & 262 & $3.49(2.13,5.72)$ & $4.01(2.07,7.79)$ \\
\hline $3-4$ & 65 & 134 & $2.99(1.74,5.14)$ & $3.11(1.38,7.00)$ \\
\hline $5+$ & 8 & 28 & $1.76(0.71,4.36)$ & $2.37(0.61,9.20)$ \\
\hline \multicolumn{5}{|l|}{ Give birth after HIV infection } \\
\hline Yes & 110 & 122 & $2.96(2.15,4.10)$ & \\
\hline No & 133 & 438 & $1: 00$ & \\
\hline \multicolumn{5}{|l|}{ Has or had an HIV-positive child } \\
\hline Yes & 6 & 54 & $1: 00$ & \\
\hline No & 24 & 42 & $5.14(1.92,13.72)$ & \\
\hline I don't know & 213 & 464 & $4.13(1.75,9.75)$ & \\
\hline
\end{tabular}


Table 4 Factors associated with contraceptive use among HIV-positive women in Amhara region referral hospitals, May 2013 (Continued)

\begin{tabular}{|c|c|c|c|c|}
\hline \multirow[t]{2}{*}{ Variables } & \multicolumn{2}{|c|}{ Contraceptive use } & \multirow[t]{2}{*}{ COR $(95 \% \mathrm{Cl})$} & \multirow[t]{2}{*}{$\mathrm{AOR}(95 \% \mathrm{Cl})$} \\
\hline & $\overline{\text { Yes }}$ & No & & \\
\hline \multicolumn{5}{|c|}{ Time since HIV diagnosis (years) } \\
\hline$\leq 1$ year & 17 & 69 & $1: 00$ & $1: 00$ \\
\hline $2-3$ years & 94 & 207 & $1.84(1.02,3.30)$ & $2.37(1.10,5.08)$ \\
\hline$\geq 4$ years & 132 & 284 & $1.88(1.06,3.33)$ & $2.63(1.23,5.61)$ \\
\hline \multicolumn{5}{|c|}{ Current CD4 count } \\
\hline$<200$ & 13 & 65 & $1: 00$ & $1: 00$ \\
\hline $200-350$ & 61 & 154 & $1.98(1.01,3.85)$ & $1.80(0.78,4.15)$ \\
\hline $351-500$ & 71 & 180 & $1.97(1.02,3.80)$ & $1.85(0.81,4.25)$ \\
\hline$>500$ & 98 & 161 & $3.04(1.59,5.80)$ & $3.25(1.42,7.44)$ \\
\hline
\end{tabular}

our study, among contraceptive users, one third (42.8\%) preferred and used male condom exclusively, while a high proportion of women preferred and used an injectable contraceptive.

Majority of women in our study preferred to used injectable contraceptive than condom and oral contraceptive unlike a study conducted in northern Uganda [26], in which the male condom was the most commonly used method $(99.4 \%)$, followed by the pill $(88.3 \%)$. This variation might be due to differences in the study participants. In the previous study, the participants were both male and females; whereas, in our study all the participants were female. Previous studies have reported that men are more dominant than women in decision making to use a condom [20, 27]. Women living with HIV infection may feel unable to negotiate condom use with sexual partners for fear of reflectance, domestic violence, loss of economic support, and social isolation $[27,28]$. The other reason for not preferring oral contraceptive in our study might be because all the study participants were ART users. Taking both ART and oral contraceptive may increase pill burdens. A survey conducted in South Africa showed a significant difference in oral contraceptive use between ART naïve and ART users [29].

Those HIV-positive women enrolled at ART clinic in Dessie Referral Hospital were $66 \%$ less likely to use contraceptive than Gondar Referral Hospital. Even though it needs farther explanation, this difference could be due to a variation in the setup and health professionals in proper counselling on condom use and other contraceptive methods at the ART clinic [30].

Women, less than 35 years of age were more likely to use contraceptive than women 40 years of age. This is because biologically older women will become menopauses and less likely to use contraceptive [21]. The other reason might be older age women have a high chance of separated or divorced from their regular partner so that they may not be sexually active $[22,31]$. As a result, they may not use contraceptive. This is supported by our finding that those single, divorced, widowed and separated women are less likely to use contraceptive as compared to married women. This finding also has significant implication for vertical as well as heterosexual transmission of HIV because a large portion of the study participants had a serodiscordant partner $(21.8 \%)$ and some did not know the HIV status of their partner (4.6\%). Besides, $2.1 \%$ of those married women had not disclosed their HIV-status to their husband. Women in such situations are less likely to take the necessary care to protect their newborn child from HIV infection [32].

In our study, monthly family income was associated with contraceptive use. Those HIV-positive women with monthly family income 300.00-600.00 EBR were less likely to use contraceptive as compared to those women with family income less than 300.00 EBR. This might be due to the fact that women with a relatively middle income may have a great desire for a child and low intention to use contraceptive [33].

Number of living children was another factor which associated with the use of contraceptive. Similar findings were reported in a study conducted in Uganda [26]. Those women with a high number of living children were more likely to use contraceptive as compared to those women with a low number of living children. This might be explained by the high level of desire for children in low family size women. The strong desire to have children in these women could be the need for future support in their chronic illness [34].

Those women who live with HIV for a long period were more likely to use contraceptive as compared to newly diagnosed women. This is because those women who live with HIV for a long period may have stabilised life in their society and become sexually active [35, 36]. Thus, they may use contraceptive to protect an unplanned 
pregnancy. In contrast, newly diagnosed women may not be socially stable, and they may not have a desire for sexual intercourse and contraceptive use [35]. The other reason might be those women who live with HIV for a long period could have a better knowledge and understanding of mother to child transmission of HIV than newly diagnosed women; as a result, they may have a desire to use contraceptive [37].

Women with a relatively high CD4 count (>500 cell/ul) were more likely to use contraceptive as compared to those women having low CD4 count $(<200$ cell/ul). This might be since women with high CD4 count could be relatively healthy and have a desire for sexual intercourse, they might use a contraceptive to prevent unplanned pregnancy.

The study had some limitation. First, due to the cross-sectional nature of the study, the temporal relationship between the explanatory and outcome variable could not be established. Second, considering that the interviews took place at the health facilities, there is a possibility of social desirability bias that may overestimate the prevalence of contraceptive use. However, this was taken care of by recruiting of data collectors out of the hospital staff. Third, this study did not exclude women who were sexually inactive, and it includes only women who are on ART. As a result, we could not see the impact of ART on contraceptive use.

\section{Conclusion}

We found that the prevalence of contraceptive use among HIV-positive women in Amhara region referral hospitals was low. This suggests a high-risk of unintended pregnancy among HIV-positive women. The most preferred contraceptive methods were injectable and male condom. We recommend that these contraceptive methods should be available for HIV-positive women and integrated with the ART clinics.

\section{Additional file}

Additional file 1: The questioner used for the data collection. (DOCX $22 \mathrm{~kb}$ )

\begin{abstract}
Abbreviations
AIDS: Acquired immune deficiency syndrome; AOR: Adjusted odd ratio; ART: Antiretroviral therapy; ARV: Antiretroviral; Cl: Confidence interval; EBR: Ethiopian birr; HIV: Human immunodeficiency virus; IQR: Interquartile range; OR: Odd ratio; PLHIV: People living with HIV; PMTCT: Prevention of mother-to-child transmission; SD: Standard deviations; VCT: Voluntary counseling and testing
\end{abstract}

\section{Acknowledgements}

The author would like to thank Management Sciences for Health/Ethiopian Network for HIV/AIDS Treatment -Care and Support program (MSH/ENHAT-CS) for the vital support. We appreciate all women who participated in this study. We also thank the data collectors and supervisors for their effort during data collection.

\section{Funding}

This study is made possible by the generous support of the United States Agency for International Development (USAID) under Cooperative Agreement No. AID-663-A-11-00006. The contents are the responsibility of the authors and do not necessarily reflect the views of USAID or the United States Government. The funder had no role in study design, data collection and analysis, interpretation of data, decision to publish, or in writing the manuscript.

\section{Availability of data and materials}

The dataset used for this study are available from the corresponding author on reasonable request.

\section{Authors' contributions \\ KAA1: conceived and designed the study, analyzed the data, and prepared the draft manuscript. KAA2: supervised the data collection process, and revised the drafted manuscript. Both authors reviewed and approved the final version of the paper.}

\section{Ethics approval and consent to participate}

Ethics approval was obtained from the Institutional Ethics Review Boards of the University of Gondar, and an official permission letter was received from each hospital administration office. To ensure confidentiality names and personal identifiers were not collected from the study participants. The anonymous data entered into computer records are password protected. All hard copy questionnaires are stored in locked filing cabinets in a secure location to which only study investigators and interviewers have access. A trained interviewer provided potential participants with sufficient information about the purpose, methods and demands of the study. Informed consent was obtained from all study participants and from caretakers or parents on behalf of the minors or children under the age of 16 years. Written consent was not feasible to get from all study participants because some of the study participants were unable to read and write. The ethics committee has approved this oral consent by considering that the type of study was harmless to the study participants.

\section{Consent for publication}

Not applicable.

Competing interests

The authors declare that they have no competing interests.

\section{Publisher's Note}

Springer Nature remains neutral with regard to jurisdictional claims in published maps and institutional affiliations.

\section{Author details}

${ }^{1}$ Institute of Public Health, College of Medicine and Health Sciences, University of Gondar, Gondar, Ethiopia. ${ }^{2}$ School of Nursing, College of Medicine and Health Sciences, University of Gondar, Gondar, Ethiopia.

Received: 2 February 2017 Accepted: 13 June 2018

Published online: 18 June 2018

\section{References}

1. Desgrees-Du-Lou A, Msellati P, Viho I, Yao A, Yapi D. Contraceptive use, protected sexual intercourse and incidence of pregnancies among African HIV-infected women. Int J STD AIDS. 2002;13:462-8.

2. Rochat TJ, Richter LM, Doll HA, Buthelezi NP, ATomkins. Depression among pregnant rural south African women undergoing HIV testing. JAMA. 2006; 295:1376-8.

3. Deneke K, Rubin J, Franklin N, Guyon A. Prevention of mother to child transmission (PMTCT) baseline survey Ethiopia. AED-LINKAGES. 2004

4. WHO. Health benefits of family planning. Geneva: WHO; 1995.

5. Reynolds HW, Janowitz B, Homan R, Johnson L. The value of contraception to prevent perinatal HIV transmission. Sex Transm Dis. 2006;33:350-6.

6. Horton R. The continuing invisibility of women and children. Lancet. 375: 1941-3.

7. WHO. Prevention of HIV in infants and young children: review of evidence and WHO's activities. Geneva: WHO; 2002. 
8. Petruney T, Robinson E, Reynolds H, Wilcher R, Cates W. Contraception is the best kept secret for prevention of mother-to-child HIV transmission. Bull World Health Organ. 2008;86(6).

9. Andia I, Kaida A, Maier M, Emenyonu DGN. Highly active antiretroviral therapy and increased use of contraceptives among HIV-positive women during expanding access to antiretroviral therapy in Mbarara, Uganda. Am J Public Health. 2009;99:340-7.

10. Kaida A, Andia I, Maier M, Strathdee SA, Bangsberg DR. The potential impact of antiretroviral therapy on fertility in sub-Saharan Africa. Curr HIV/AIDS Rep. 2006;3:187-94.

11. FMOH: Accelerated plan for scaling up prevention of mother to child transmission (PMTCT) Services in Ethiopia. 2011.

12. Joseph P, Desai VBR, Mohan NS, Fredrick JS, Ramachandran R, Raman B, Wares F, Ramachandran $\mathrm{R}$, Thomas A. Outcome of standardized treatment for patients with MDR-TB from Tamil Nadu, India. Indian J Med Res. 2011;133(5):529.

13. FDRE: Country progress report on HIV/AIDS response. 2012.

14. UNICEF: Global plan towards eliminating new infections among children by 2015 and keeping their mothers alive. Geneva, Switzerland 2011.

15. Federal HIV/AIDS Prevention \& Control Office. Multi-sectoral HIV/AIDS response monitoring and evaluation report 2011.

16. USAID: Ethiopia: HIV/AIDS health profile. 2012

17. CSA. Population projection of Ethiopia for all regions at wereda level from 2014-2017. Addis Ababa: Central Statistical Agency of Ethiopia; 2013.

18. Tamene W, Fantahun M. Fertility desire and family-planning demand among HIV-positive women and men undergoing antiretroviral treatment in Addis Ababa, Ethiopia. African J AIDS Res. 2007;6(3):223-7.

19. CSA I. Ethiopia Demographic and Health Survey 2016. Addis Ababa, Ethiopia, and Rockville, Maryland, USA: Central Statistical Agency (CSA) [Ethiopia] and ICF; 2016.

20. Feldblum, Welsh MJ, Steiner MJ. Don't overlook condoms for HIV prevention. Sex Transm Infect. 2003;79:268-9.

21. Allen $\mathrm{RH}$, Cwiak CA, Kaunitz AM. Contraception in women over 40 years of age. Can Med Assoc J. 2013;185(7):565-73.

22. Karraker A, DeLamater J, Schwartz CR. Sexual frequency decline from midlife to later life. J Gerontol B Psychol Sci Soc Sci. 2011;66((4):502-12.

23. Kaida A, Laher F, Strathdee SA, Money D, Janssen PA, Hogg RS, Gray G. Contraceptive use and method preference among women in Soweto, South Africa: the influence of expanding access to HIV care and treatment services. PLoS One. 2010;5(11):e13868.

24. Alene KA. Consistent condom use among sexually active HIV positive women in Amhara region, Ethiopia. Open Access J Contracept. 2014;5:85-90

25. UN: World Contraceptive Use. New York: Department of Economic and Social Affairs, Population Division; 2007.

26. Nattabi B, Li J, Thompson SC, Orach CG, Earnest J. Family planning among people living with HIV in post-conflict northern Uganda: a mixed methods study. BioMed Central Conflict and Health. 2011;5(18)

27. Harvey SM, Bird ST, Galavotti C, Duncan EA, Greenberg D. Relationship power, sexual decision making and condom use among women at risk for HIV/STDs. Women Health. 2002;36(4):69-84.

28. Teitelman AM, Ratcliffe SJ, Dichter ME, Sullivan CM. Recent and past intimate partner abuse and HIV risk among young women. J Obstet Gynecol Neonatal Nurs. 2008;37(2):219-27.

29. Kaida A, Laher F, Strathdee SA, Money D, Janssen PA, Hogg RS, Gray G. Contraceptive use and method preference amongWomen in Soweto, South Africa: the influence of expanding access to HIV care and treatment services. PLoS One. 2010;5(11):e13868.

30. Gelaw YA, Biks GA, Alene KA. Effect of residence on mothers' health care seeking behavior for common childhood illness in Northwest Ethiopia: a community based comparative cross-sectional study. BMC research notes. 2014;7(1):705.

31. Kennedy S, Ruggles S. Breaking up is hard to count: the rise of divorce in the United States, 1980-2010. Demography. 2014;51(2):587-98.

32. Spangler SA, Onono M, Bukusi EA, Cohen CR, Turan JM. HIV-positive status disclosure and use of essential PMTCT and maternal health services in rural Kenya. J Acquir Immune Defic Syndr. 2014;67(Suppl 4):S235

33. Augustine JM, Nelson T, Edin K. Why do poor men have children? Fertility intentions among low-income unmarried US fathers. Ann Am Acad Pol Soc Sci. 2009;624(1):99-117.

34. Gallant MP, Spitze G, Grove JG. Chronic illness self-care and the family lives of older adults: a synthetic review across four ethnic groups. J Cross Cult Gerontol. 2010;25(1):21-43.
35. Gelaw YA, Senbete GH, Adane AA, Alene KA. Determinants of late presentation to HIV/AIDS care in southern Tigray zone, northern Ethiopia: an institution based case-control study. AIDS Res Ther. 2015;12(1):40.

36. Schackman BR, Dastur Z, Ni Q, Callahan MA, Berger J, Rubin DS. Sexually active HIV-positive patients frequently report never using condoms in audio computer-assisted self-interviews conducted at routine clinical visits. AIDS Patient Care STDs. 2008;22(2):123-9.

37. Birhane T, Assefa Tessema G, Addis Alene K, Dadi AF. Knowledge of pregnant women on mother-to-child transmission of HIV in Meket District, Northeast Ethiopia. J Pregnancy. 2015;2015:101-7.

\section{Ready to submit your research? Choose BMC and benefit from:}

- fast, convenient online submission

- thorough peer review by experienced researchers in your field

- rapid publication on acceptance

- support for research data, including large and complex data types

- gold Open Access which fosters wider collaboration and increased citations

- maximum visibility for your research: over $100 \mathrm{M}$ website views per year

At BMC, research is always in progress.

Learn more biomedcentral.com/submissions 